\title{
Condition monitoring of hydraulic cylinder seals using acoustic emissions
}

\author{
Vignesh V. Shanbhag ${ }^{1} \cdot$ Thomas J. J. Meyer $^{1} \cdot$ Leo W. Caspers ${ }^{2} \cdot$ Rune Schlanbusch $^{1}$
}

Received: 8 April 2020 / Accepted: 6 July 2020 / Published online: 21 July 2020

(C) The Author(s) 2020

\begin{abstract}
In recent years, there has been a growing concern for fluid spill from hydraulic cylinders in the offshore oil and gas industry. To diagnose the leakage from hydraulic cylinders, there have been attempts made in literature using fluid and pressure-based condition monitoring techniques. However, there have been limited attempts to monitor leakage from hydraulic cylinders using acoustic emissions. Therefore, in this paper, an attempt has been made to understand the fluid leakage in the hydraulic cylinder based on acoustic emissions. An experimental study was performed using a test rig (with a water-glycol as hydraulic fluid) which closely replicates the operation of a hydraulic cylinder. As piston rod seal failure is the foremost cause for leakage, experiments were performed using unworn, semi-worn, and worn piston rod seals. For each seal condition, experiments were performed for five strokes at pressure conditions of 10,20,30, and 40 bar. In this study, the continuous acoustic emission signal was observed for each hydraulic cylinder stroke. Acoustic emission data was analysed using different techniques such as time domain, frequency domain, and time-frequency technique. By using acoustic emission features such as root mean square (RMS), peak, skewness, median frequency, and mean frequency, it was possible to identify and separate non-leakage and leakage conditions in the test rig. By using AE bandpower and power spectral density features, it is also possible to identify the leakage due to semiworn seal and worn seal in the test rig. This study lays a strong basis to develop a real-time monitoring technique based on acoustic emissions to monitor the health of piston rod seals used in the hydraulic cylinder in the offshore industry.
\end{abstract}

Keywords Hydraulic cylinder · Piston rod seal $\cdot$ Acoustic emission $\cdot$ Power spectral density $\cdot$ Bandpower

\section{Introduction}

Hydraulic cylinders are indispensable in the offshore oil and gas $(O \& G)$ industry. Hydraulic cylinders are used for material handling, clamping units, skidding systems, heave

Vignesh V. Shanbhag

vigs@ norceresearch.no

$\triangle$ Rune Schlanbusch

rusc@ norceresearch.no

Thomas J. J. Meyer

thme@ norceresearch.no

Leo W. Caspers

leo.caspers@boschrexroth.nl

1 Norwegian Research Centre AS, Jon Lilletuns vei 9 H, 3. etg, 4879 Grimstad, Norway

2 Bosch Rexroth B.V., Kruisbroeksestraat 1, 5281, RV Boxtel, The Netherlands compensation and tensioning and oil drilling equipment. Leakage from the hydraulic cylinders is a major concern for the $O \& G$ industry. One of the primitive causes of leakage from the hydraulic cylinders is due to failure of piston rod seals. Piston rod seals are used for fluid sealing and are placed inside the cylinder head. The piston rod seal is pressed against the cylinder rod, preventing the fluid to flow from the cylinder head [1]. Untimely failure of the piston rod seals can lead to severe consequences such as fluid spill, machine downtime, and repair cost. Replacing the seal before the point of catastrophic failure is less expensive compared with the seal replacement after the point of failure [2]. As the piston rod seal is placed inside the cylinder head, visual inspection of seal degradation is difficult. A real-time continuous inspection method of seal degradation will enable condition monitoring of hydraulic cylinders on this aspect.

Condition monitoring of hydraulic cylinders reduces machine downtime and maintenance cost. Numerous condition monitoring studies have been conducted to monitor the failure of hydraulic cylinders. For example, Goharrizi et al. [3] and 
Tang et al. [4] investigated internal leakage in hydraulic actuators using pressure sensors. Goharrizi et al. [3] used a wavelet-based method to identify internal leakage inside a hydraulic actuator. Wavelet decomposition of the pressure signal was performed using multiresolution signal decomposition and a quadrature mirror filter technique. The RMS feature from the level two detail wavelet coefficients was observed to show sensitivity to the healthy and faulty conditions. Tang et al. [4] used energy from the frequency bands after wavelet decomposition to classify the severity of leakage conditions. $\mathrm{Ng}$ et al. [5] monitored the wear of hydraulic components using hydraulic oil contamination analysis. Oil from a construction machine was tested using portable particle counters according to ISO 4406 and using an inductively coupled plasma or optical emission spectroscopy equipment (ICP/OES). In comparison, it was observed that ICP/OES offers higher resolution compared with the standards defined in ISO 4406 in terms of measuring the size and quantity of metallic particles. Ramachandran et al. [6] performed prognostic studies of rotary seals using the torque metre. Torque signal was analysed using statistical time-domain features such as mean, RMS, peak, and square mean rooted absolute amplitude (SRA). Using the timedomain features, it was possible to understand different stages of seal wear such as healthy, slightly worn, significant wear and failed condition. Helwig et al. [7] investigated condition monitoring of hydraulic systems using the linear discriminant analysis to identify the type and severity of faults. Pressure, flow, temperature, electrical power, vibration, fluid parameter monitoring, and particle contamination sensors were used in this study. Statistical features such as median, variance, skewness, and kurtosis were used as an input to the linear discriminant analysis. From the literature, it is evident that a sufficient number of studies have been conducted to monitor defects in hydraulic cylinders using different sensors. However, limited attempts have been made to monitor hydraulic cylinder using acoustic emissions (AE).

An advantage of AE-based condition monitoring is that $\mathrm{AE}$ signals are sensitive to damage on the microscopic level and largely not affected by the environmental noise or machine vibrations due to their high frequency range, which is normally between $50 \mathrm{kHz}$ and $2 \mathrm{MHz}$ [8]. AEbased condition monitoring has been used to detect and localize leakage in different applications. For example, Morofuji et al. [9] analysed the AE signal to detect leakage from a water tank. Using the AE amplitude features, it was possible to distinguish water leakage and corrosion conditions. Ahadi et al. [10] used AE to detect leakage through plastic pipes. Due to the high frequency range of the $\mathrm{AE}$ signal, it was possible to identify the natural frequency of the pipe, splash, and environmental noise. There have also been attempts to monitor leakage in hydraulic cylinder using AE. For example, Chen et al. [8] used AE to monitor leakage in water hydraulic cylinders. AE features such as count, RMS, and power spectral density were used to monitor leakage in hydraulic cylinders.

From the literature, we can note that very few attempts have been made to monitor leakage due to piston rod seal failure of the hydraulic cylinder using AE. Therefore, in this study, leakage resulting from the failure of the piston rod seal of hydraulic cylinders will be investigated using AE. Different AE features were analysed to determine the AE feature that can separate the piston rod seal conditions (unworn, semi-worn, and worn seal) in the seal flange irrespective of the pressure conditions. To meet the objective, a series of experiments were conducted using unworn, semi-worn, and worn piston rod seals. For each seal condition, experiments were performed at different pressure conditions. To separate the non-leakage and leakage conditions of piston rod seals, the AE signal was analysed using AE features such as mean, RMS, peak, kurtosis, skewness, mean frequency, median frequency, power spectral density, and bandpower.

\section{Experimental details}

\subsection{Experimental setup}

Experiments were performed on a test rig with a hydraulic cylinder head. The setup used in this study closely replicates fluid leakage conditions that are typically observed in a hydraulic cylinder. Figure 1a and b represent the circuit diagram and schematic view of the setup that was used for the experimental study. The test rig consists of an electromechanical cylinder, which uses a spindle and nut to convert rotation to translation and a servomotor to drive the spindle. The motor is equipped with an encoder to control the rod position. The rod and the head of this cylinder are designed to simulate the situation of a hydraulic cylinder. The rod travels through a pressurized flange that contains the elements normally found in the head of a hydraulic cylinder such as bearing strips and seals. As shown in Fig. 1c, piston rod seals were placed at both ends of the cylinder head to act as fluid sealing and with three bearing strips in between to withstand arising side loads, which are not present in this setup. A hydraulic power pack supplies the pressurized fluid to the flange. The pressure is controlled by a pressure control valve. To perform the condition monitoring studies, only the upper piston rod seal was replaced with unworn, semi-worn, and worn piston seals. The seal name was Stepseal 2A supplied by Trelleborg sealing solutions. Figure 1d represents the piston rod seals used in this study. The unworn seal had no scratches, the semi-worn seal had very minor scratches, and the worn seal had major scratches.

For each seal condition, experiments were performed at 10 , 20, 30, and 40 bar for five cylinder strokes in each. The motor 
a)

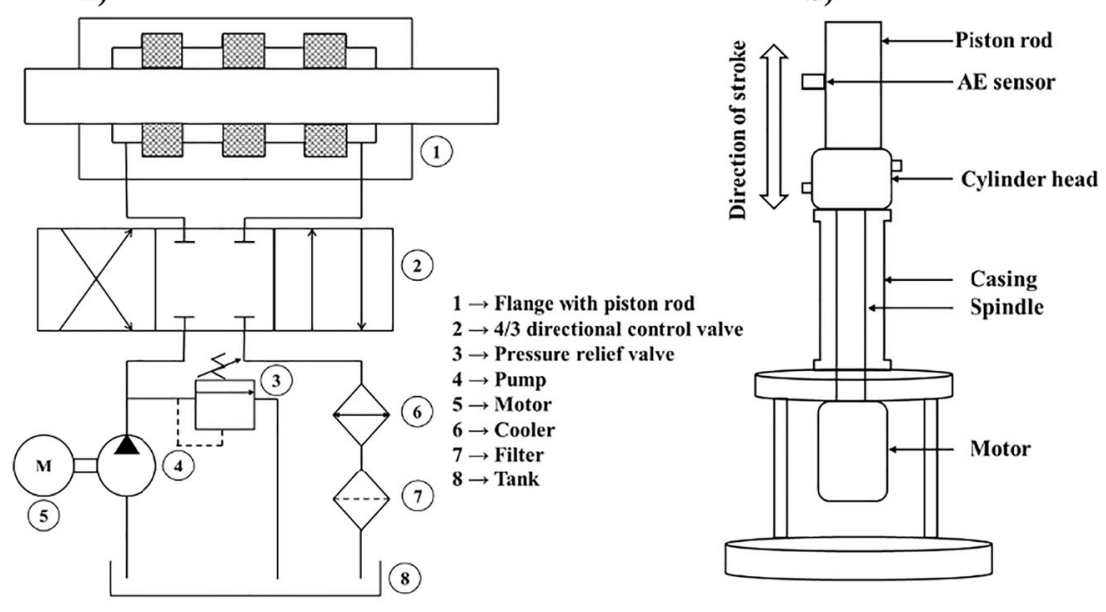

c)

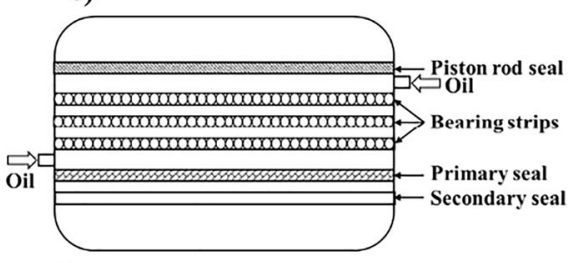

d)

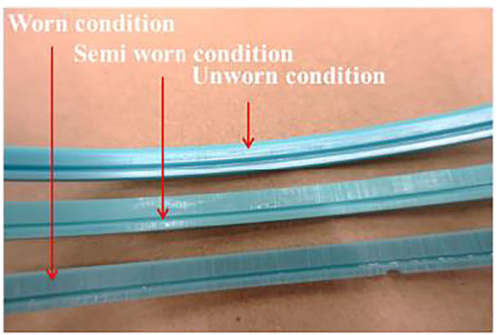

Fig. 1 a Circuit diagram of cylinder setup. b Schematic view of hydraulic test rig, c Front view of seal arrangement in cylinder head. d Piston rod seals used in this study

encoder was used to record the number of hydraulic cylinder strokes. There is a time gap of $1 \mathrm{~s}$ at the end of each hydraulic cylinder stroke in between extraction and retraction and vice versa. The remaining process parameters used in this study were kept constant and are summarized in Table 1.

\subsection{Data acquisition setup}

The piston rod seal placed in the cylinder head was in direct contact with the piston rod. Therefore, as shown in Fig. 1b, the AE sensor was placed on the piston rod using an adhesive bond and industrial duct tape to secure a good signal path. The AE sensor used in this study was a midfrequency range sensor, having an operating $\mathrm{AE}$ frequency range of $50-400 \mathrm{kHz}$ and $\mathrm{AE}$ resonant frequency of $150 \mathrm{kHz}$ (type: R15a, supplier: physical acoustics). The

Table 1 Process parameters

\begin{tabular}{ll} 
Seal material & $\begin{array}{l}\text { Polyether-based polyurethane elastomer } \\
\text { Cladded coating of a cobalt-based alloy } \\
\text { Coating on piston rod }\end{array}$ \\
Seal size & Water glycol \\
Fluid & $50 \mathrm{~mm} / \mathrm{s}$ \\
Speed & $10,20,30,40 \mathrm{bar}$ \\
Pressure & $600 \mathrm{~mm}$ \\
Stroke length & 5 \\
Number of strokes & Unworn, semi-worn, worn \\
Seal condition & $1 \mathrm{MS} / \mathrm{s}$ \\
Data acquisition speed & 1 \\
Number of AE sensors & $40 \mathrm{~dB}$ \\
AE amplifier gain & \\
\hline
\end{tabular}

$\mathrm{AE}$ sensor was connected to the data acquisition setup via a gain selectable pre-amplifier with selected gain of $40 \mathrm{~dB}$ (type: 0/2/4-switch selectable gain single ended and differential pre-amplifier, supplier: physical acoustics). A continuous AE signal with a sampling frequency of $1 \mathrm{MS} / \mathrm{s}$ was recorded for each experiment. Due to large file size, at the end of five hydraulic cylinder strokes, the experiment was stopped to allow the AE data to be recorded in the computer memory. Figure 2 depicts the AE data acquisition methodology adopted in this study.

\subsection{Pencil lead break test}

The Hsu-Nielsen pencil lead break test was performed at the start of each experiment when the piston rod seal was replaced in the cylinder head. The pencil lead break test was performed to assess the effect of background noise on the AE signal and to verify sufficient signal transfer between the $\mathrm{AE}$ sensor and the cylinder head. For each pencil lead break test, a $2 \mathrm{H}$ pencil lead with diameter of $0.5 \mathrm{~mm}$ was pressed against the piston rod. From Fig. 3a, it is evident that the maximum AE amplitude of the burst signal generated from the pencil lead break test is very high compared with the machine noise $(0-0.25$ $\mathrm{ms})$. Similarly, as observed in Fig. $3 \mathrm{~b}$ in the time-frequency representation of the $\mathrm{AE}$ signal analysed using short-time Fourier transform (STFT), the AE power is dominant after $0.25 \mathrm{~ms}$ and is observed in the frequency range of $0-500$ kHz. As observed in Fig. $3 a$ and $b$ in the time range of 0 $0.25 \mathrm{~ms}$, the impact of background noise on the AE signal is very minimal. If the similar amplitude of $A E$ burst signal and $\mathrm{AE}$ frequency distribution was not observed, then the $\mathrm{AE}$ sensor was removed and fixed again with a sufficient amount of adhesive bond. 
Fig. 2 AE data acquisition methodology

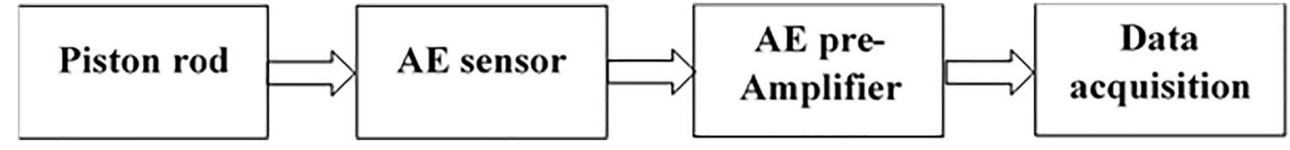

\subsection{AE signal segregation and analysis}

The AE signal was processed to segregate between each extraction and retraction of the cylinder. Similarly, the AE signal due to the extension and retraction of the rod was segregated. For AE signal analysis, the AE signals from the first and the last strokes were excluded. Only the AE signals from the second, third, and fourth strokes were considered for further AE analysis, to avoid any starting and stopping phenomena in the data set.

The AE signals obtained from the movement of the piston rod were analysed using different AE time-domain features such as mean, root mean square (RMS), peak, kurtosis, and skewness. To understand the frequency information of the piston rod seal, the AE signal was also analysed using the shorttime Fourier transform (STFT) technique. The AE signal was also analysed using $\mathrm{AE}$ frequency domain features such as mean frequency, median frequency, power spectral density, and bandpower. The techniques used for $\mathrm{AE}$ analysis in this study have been extensively discussed in literature [2, 11-13]. Therefore, only the application of AE features is discussed in this study. The AE features were calculated for each stroke and an average of the $\mathrm{AE}$ feature was estimated for each pressure condition along with standard deviation to understand the robustness with respect to time-varying operating conditions.

\section{Results and discussion}

\subsection{Leakage}

Figure 4 presents the images of the piston rod surfaces from the experiments conducted using unworn, semi-worn, and worn seals. In this study, the leakage was defined when the water glycol was visible on the piston rod. For the unworn seal condition, leakage was not observed (see Fig. 4a). For the semi-worn seal, the leakage was visible on the rod as indicated in Fig. 4b. Whereas, for the worn seal, the leakage was visible on the piston rod surface and was also observed from the leakage port (see Fig. 4c). As each test was performed for a short duration (5 strokes), quantification of the leakage was not performed in this study. This explanation of the leakage condition will be used later to qualitatively correlate and define the AE signal and AE features for the unworn, semi-worn, and worn piston rod seals.

\subsection{AE signal from the rod}

From Fig. 5, we can observe that the continuous AE signal was observed for each stroke. Figure 5a represents the $\mathrm{AE}$ signal obtained for five consecutive strokes. As observed in Fig. 5b, each stroke (extension and retraction) lasted $25 \mathrm{~s}$ in total. From Fig. 5c and d, we can observe that the extension retraction strokes lasted for $12 \mathrm{~s}$ each. The AE amplitude range for extension and retraction strokes was nearly the same $(\approx 0.2 \mathrm{~V})$. From Fig. 5a, a similar AE amplitude range was observed for extension and retraction for all the strokes for the experiments conducted with unworn seal. Therefore, only the AE signal analysed from the extension stroke is presented in the remaining analysis.

\subsection{AE signal from different seal conditions}

To understand the behaviour of the AE signal for unworn, semiworn, and worn seals, the AE signal from the extension stroke
Fig. 3 a Time-domain AE signal. b Time-frequency representation of AE signal from panel a using STFT method
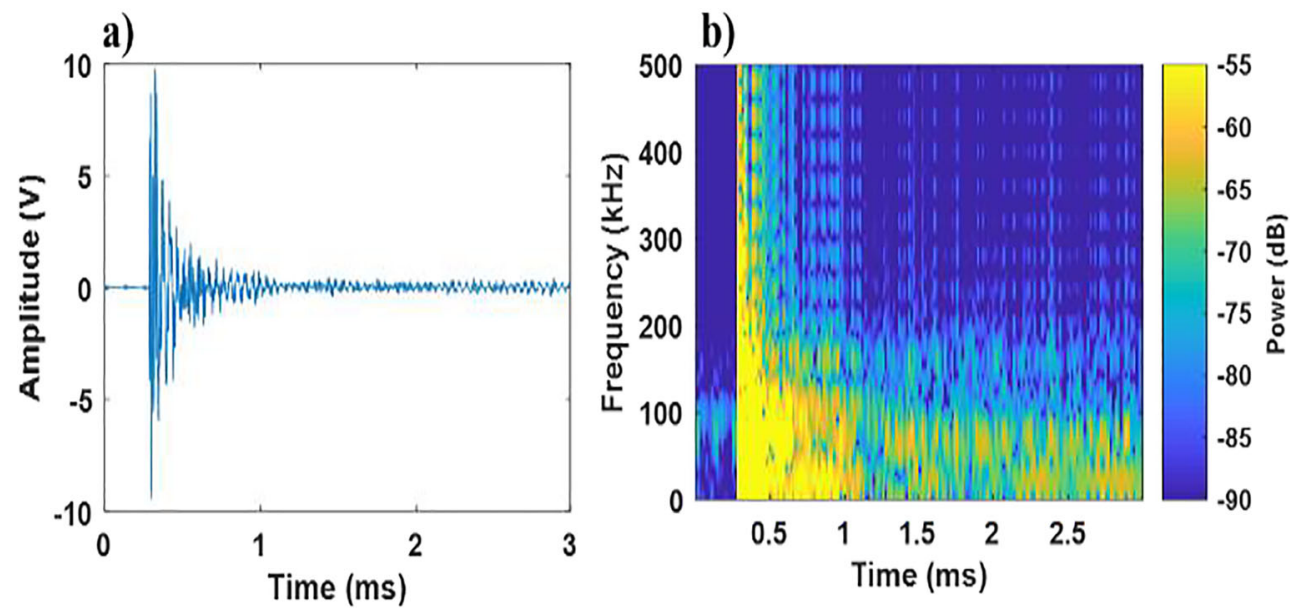
a)

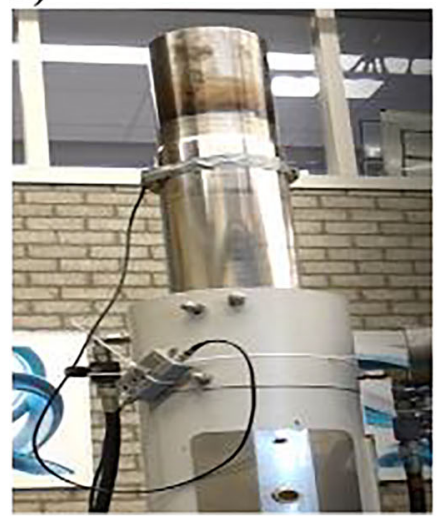

b)

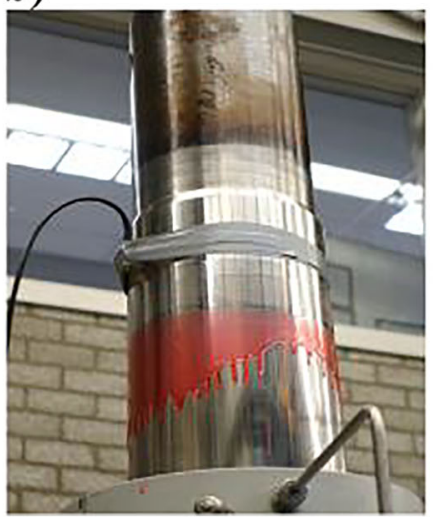

c)

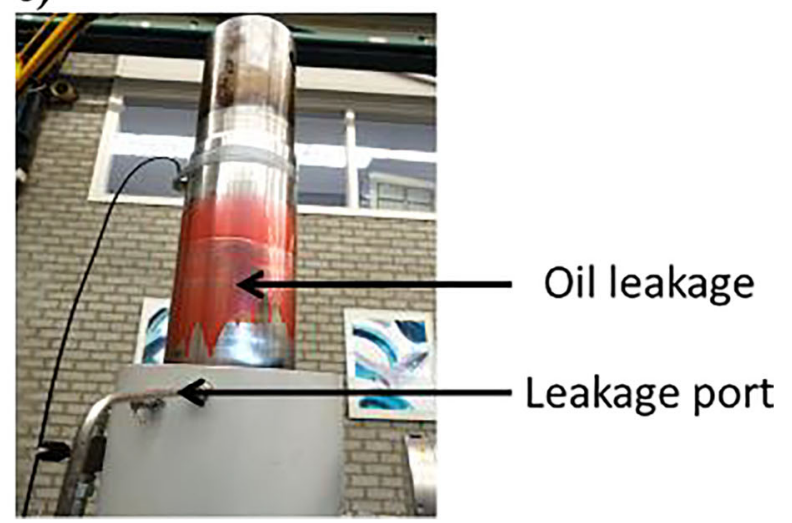

Fig. 4 Experiments conducted using a unworn seal, $\mathbf{b}$ semi-worn seal, $\mathbf{c}$ worn seal. (Note: leakage (in red) on the rod in panels $\mathbf{b}$ and $\mathbf{c}$ )

was analysed. Figure 6 represents the AE signal obtained from extension stroke for the experiments conducted using unworn, semi-worn, and worn seals. The AE amplitude for the unworn seal is observed in the range of $0.1-0.2 \mathrm{~V}$ (see Fig. 6a). For the semi-worn and worn seals, the $\mathrm{AE}$ amplitude is observed in the range of $0.4-0.6 \mathrm{~V}$ (see Fig. 6b, c). From Figs. $4 \mathrm{~b}$ and $\mathrm{c}$ and $6 \mathrm{~b}$ and $\mathrm{c}$, a good qualitative correlation can be observed between the leakage conditions and the $\mathrm{AE}$ signal behaviour. By comparing the AE amplitude from the unworn and worn seals, it is possible to identify non-leakage and leakage conditions of the seal flange. However, the AE signal due to leakage from the semi-worn seal and worn seal is not clear. Therefore, the AE signal is further analysed using different techniques.

\subsection{AE analysis}

\subsubsection{AE time-domain features}

Figure 7 represents the AE statistical features used to identify non-leakage and leakage conditions of the seal flange in the test rig. These AE statistical features were calculated using an average of three strokes. From the AE time-domain features such as mean, RMS, peak, and skewness, it was possible to separate non-leakage and leakage conditions of the seal flange. The behaviour of the AE features such as mean and RMS for the semi-worn and worn seals are nearly the same. From the AE statistical features for the unworn, semi-worn,
Fig. 5 AE signal from experiment conducted using unworn seal, 20 bar pressure. a Five strokes. b One stroke. c Extension. d Retraction a)

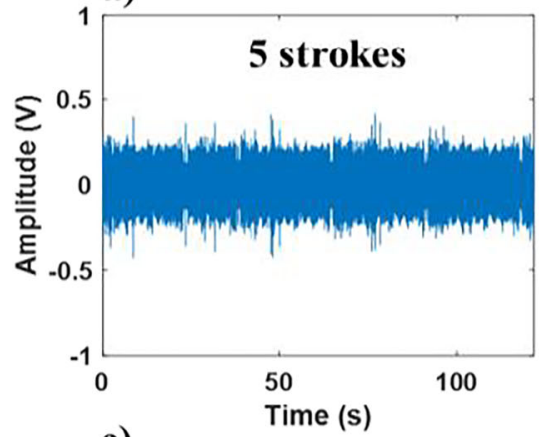

c)

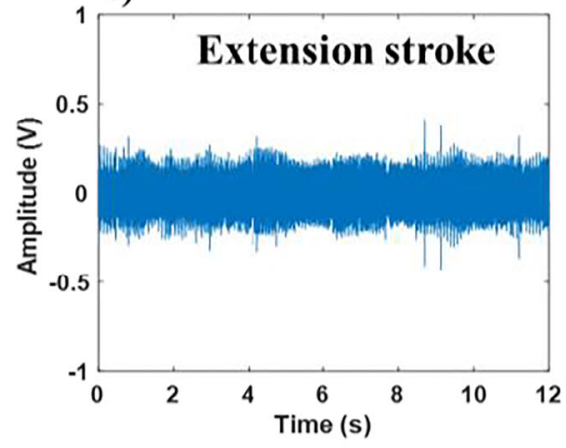

b)

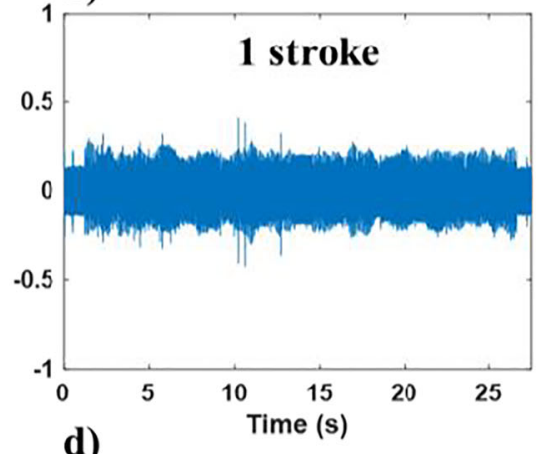

d)

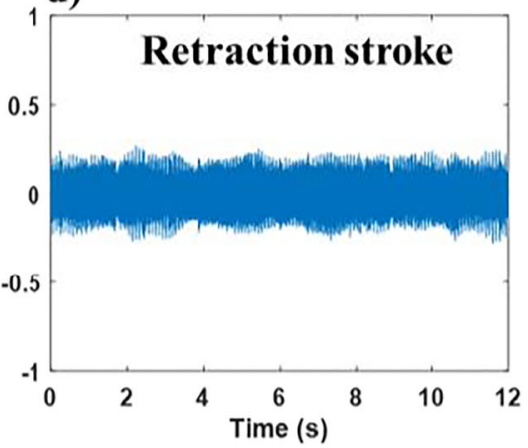


Fig. 6 AE signal from extension cylinder stroke for experiments conducted at 40 bar using a unworn seal, b semi-worn seal, and $\mathbf{c}$ worn seal a)

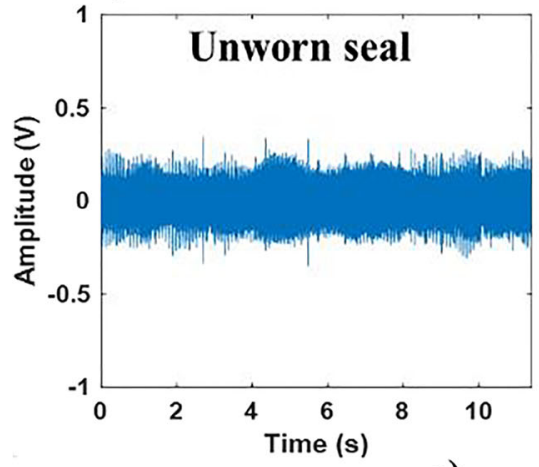

b)

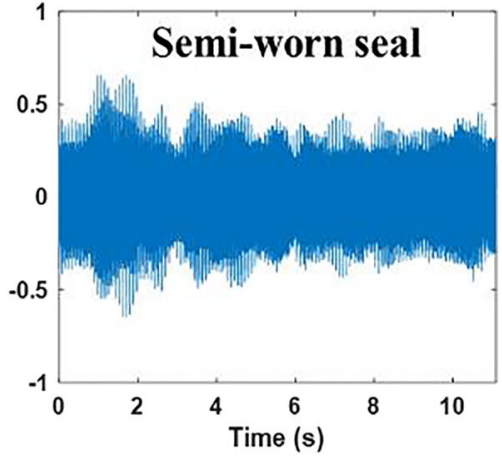

c)

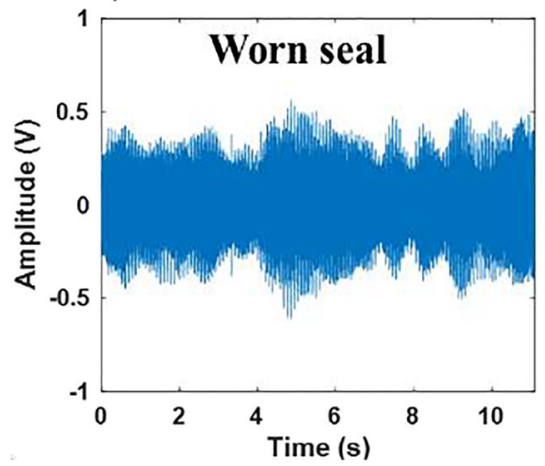

and worn seal conditions (Fig. 7), irrespective of the pressure conditions, the AE features such as mean, RMS, peak, and skewness are able to separate the non-leakage (unworn seal) and leakage (semi-worn and worn seals) conditions in the seal flange. The standard deviation from Fig. 7 is minimal for all the AE time-domain features. Therefore, the reliability of the AE features such as mean, RMS, peak, and skewness is high and can be used to identify non-leakage and leakage conditions of the seal flange.

\subsubsection{AE time-frequency analysis}

The window size for the time-frequency analysis using the STFT technique depends on the type of application $[14,15]$. a)
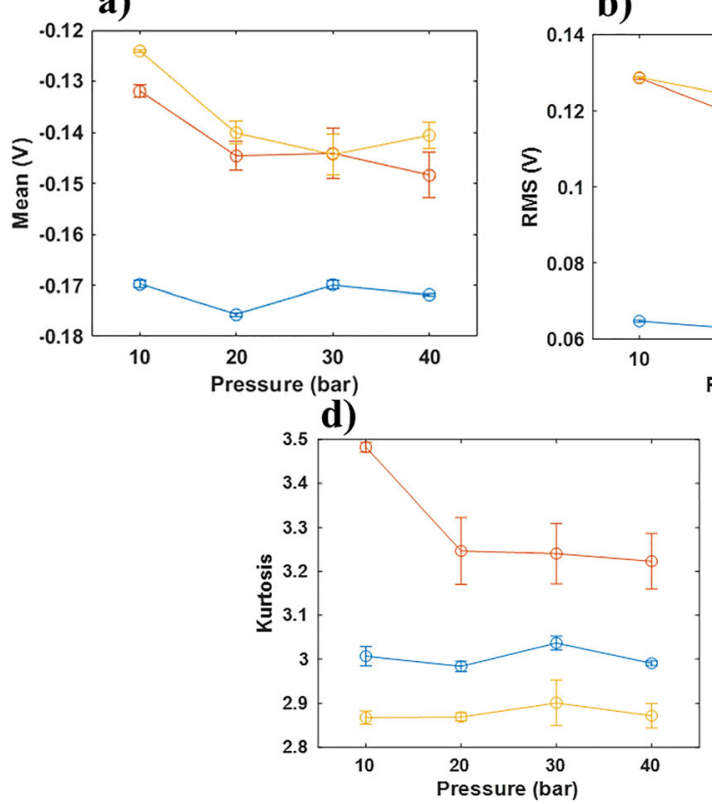

b)

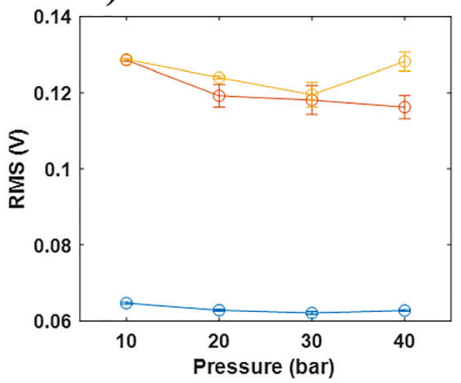

e) c)

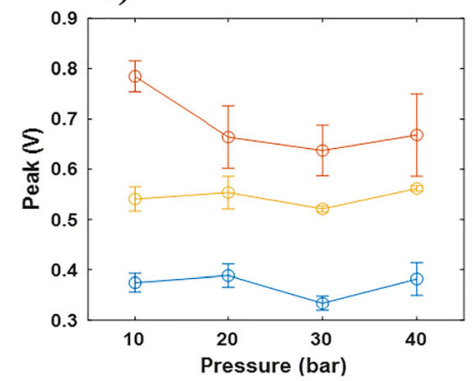

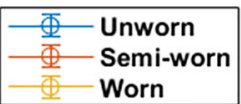

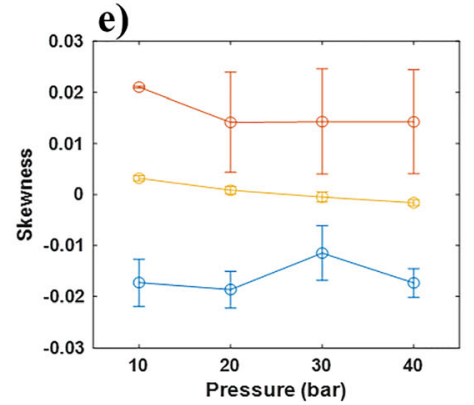

Fig. 7 AE statistical features. a Mean. b RMS. c Peak. d Kurtosis. e Skewness 
Therefore, an attempt was made to determine the appropriate window size for the STFT analysis of the AE signal. Figure 8 represents the STFT analysis of the AE signal obtained from the semi-worn seal at the pressure condition of $30 \mathrm{bar}$, for the different window size of 64, 100, 128, 256, and 512. From Fig. $8 \mathrm{a}-\mathrm{e}$, it is evident that, with the increase in window size, the time resolution deteriorates as longer window size tends to average more compared with the shorter windows [16]. In a comparison of STFT plots for window sizes 100 and 128, the time resolution of the AE signal is good; however, the lowintensity peaks highlighted in Fig. 8b are not clearly visible in Fig. 8c. Also, with a further decrease in window size (Fig. 8a), the time resolution becomes coarse and computation time increases. Therefore, the window size of 100 is selected for the STFT analysis in this study.

Figure 9 represents the time-frequency representation of the AE signal obtained from the test rig with unworn, semiworn, and worn seals for the pressure conditions of 10, 20,30, and 40 bar. From the Fig. 9a and d, for the unworn seal, we can observe that there are two frequency bands in the $\mathrm{AE}$ frequency range of $0-30 \mathrm{kHz}$ and $50-100 \mathrm{kHz}$. These AE frequency bands are likely due to the events that occur due to bearing strips and piston rod seals in the cylinder head, as shown in Fig. 1c. Similarly, from the time-frequency plot for the experiments conducted using semi-worn seal (Fig. 9e-h) and worn seal (Fig. 9i-1), there are two AE frequency bands $(0-30 \mathrm{kHz}$ and $50-200 \mathrm{kHz})$. It is important to note that the power intensity in the AE frequency range of 0-30 kHz nearly remains the same for the tests conducted with unworn, semiworn, and worn seal. The power intensity in the AE frequency range of $50-100 \mathrm{kHz}$ in Fig. 9e-h and $\mathrm{i}-1$ is higher when compared with that in Fig. 9a-d. This indicates that, due to the wear in the piston rod seal, the power intensity increases. Therefore, it is possible to identify the non-leakage (unworn seal) and leakage (semi-worn and worn seal) conditions in the hydraulic test rig. However, from the qualitative observation of time-frequency plots in Fig. 9e- $\mathrm{h}$ and $\mathrm{i}-1$, the difference is power intensity in the AE frequency range of $50-100 \mathrm{kHz}$ of the leakage due to semi-worn seal and worn seal being not clear. Therefore, further AE analysis is required to understand the quantitative difference between unworn seal in test rig and leakage due to semi-worn and worn seal in the test rig.

\subsubsection{AE frequency features}

In Fig. 9, from the STFT plot, it is difficult to quantify the difference due to leakage from the semi-worn and worn seal. Therefore, AE power spectral density is calculated to quantify

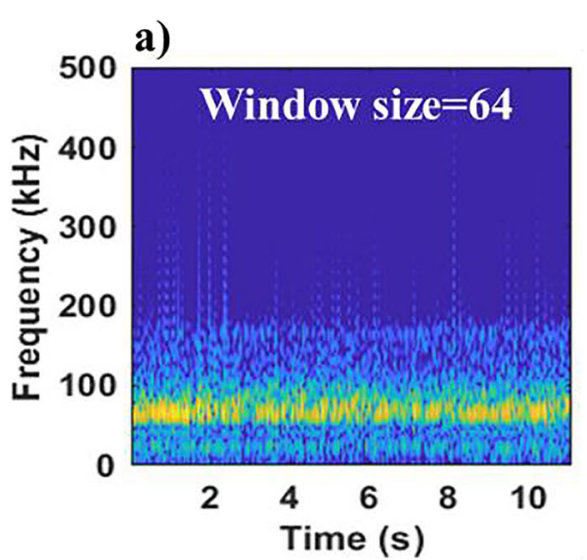

d)

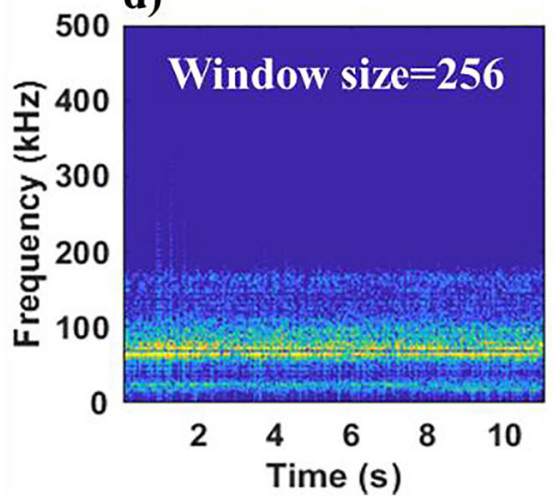

b)

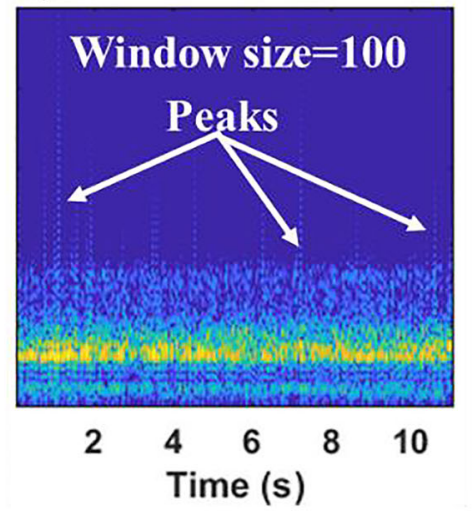

c)

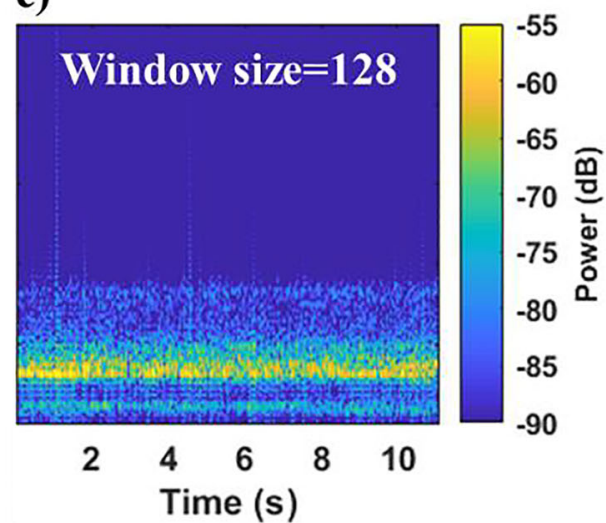

e)

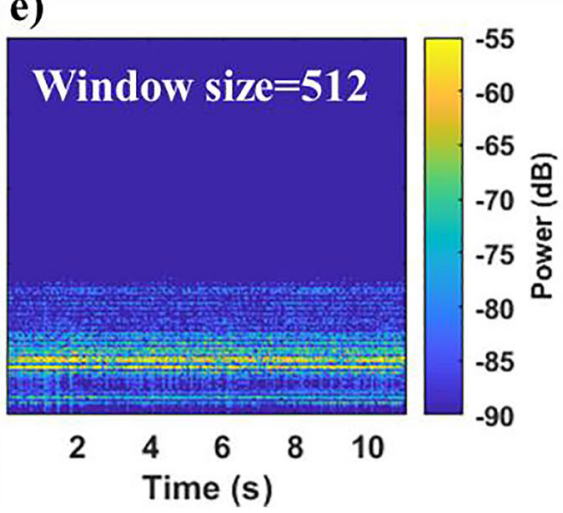

Fig. 8 Time-frequency analysis using STFT technique at window size of a 64, b 100, c 128, d 256, e 512. (Note: Window type for STFT analysis: Kaiser, seal: semi-worn, pressure: 30 bar) 

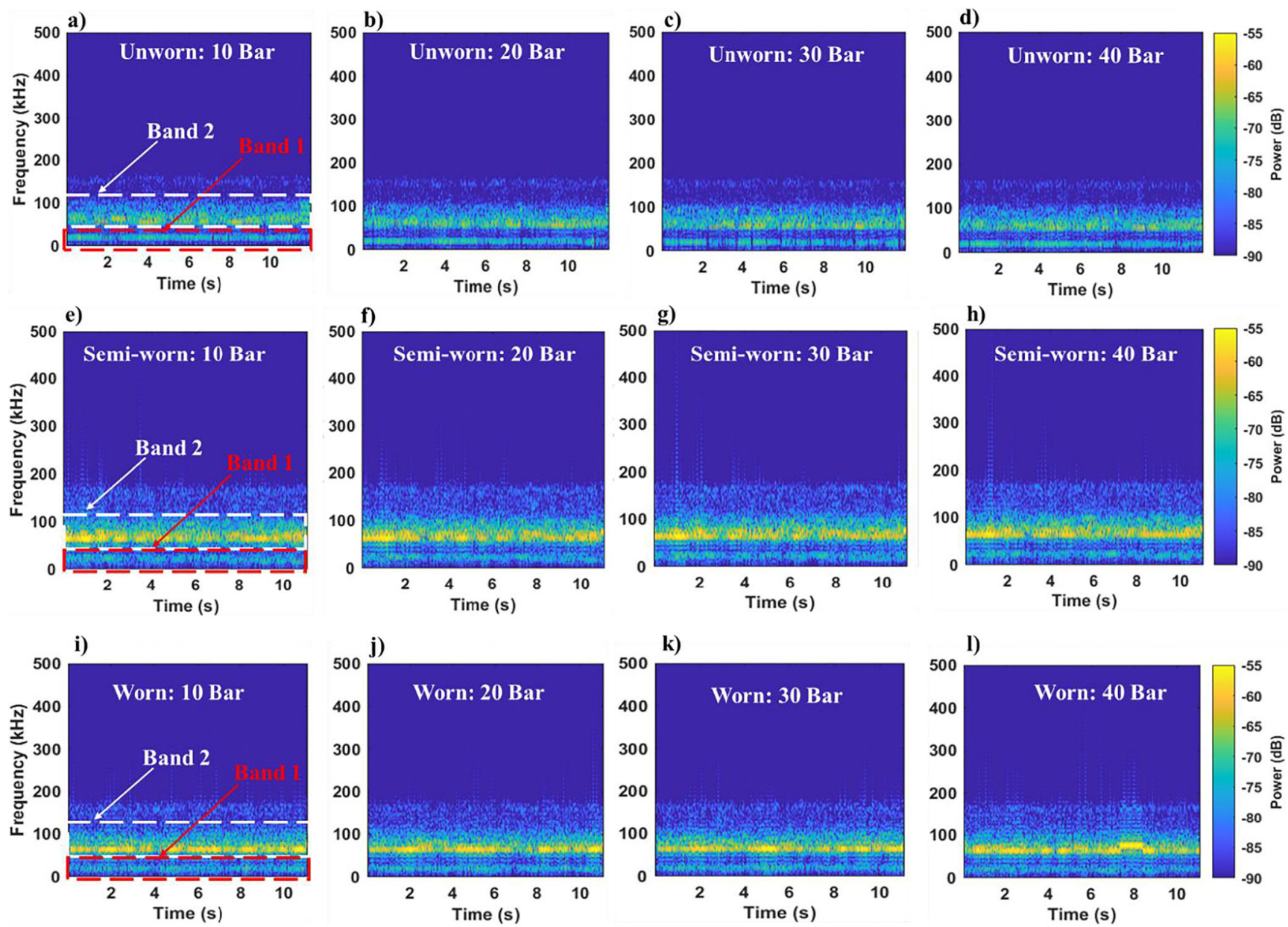

k)

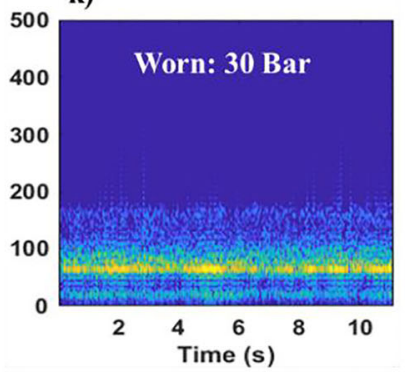

l)

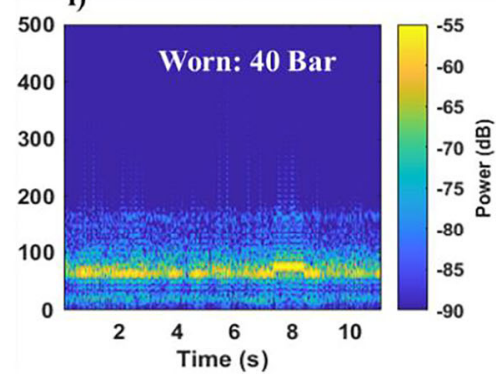

Fig. 9 Time-frequency analysis using STFT technique at pressure condition of 10, 20, 30, and 40 bar for a-d unworn seal, e- $\mathrm{h}$ semi-worn seal, and i-1 worn seal

the difference between the non-leakage condition in the test rig and to quantify the difference between the leakage due to semi-worn seal and worn seal in the test rig. Figure 10 represents the AE power spectral density plot for the unworn, semiworn, and worn seals. The magnitude of the AE frequency plot for the experiments conducted using unworn, semi-worn, and worn seals is nearly the same in the AE frequency range of $0-30 \mathrm{kHz}$ for all the pressure conditions. Therefore, similar to Fig. 9, we can reconfirm that the AE frequency range of $(0-30$ $\mathrm{kHz}$ ) is due to bearing event in the cylinder head and not due to the event occurring due to piston rod seal interaction. For all the pressure conditions, the magnitude of the frequency plot of worn seal > semi-worn seal > unworn seal is in the AE frequency range of 50-100 kHz. For the non-leakage condition (unworn seal), the maximum magnitude of the peak is $\approx 0.2 \mathrm{e}$ -6 , and for the leakage condition with the semi-worn and worn seals, the maximum magnitude of the peak is $\approx 1 \mathrm{e}-6$ and $\approx 1.2 \mathrm{e}-6$ respectively. However, with increasing pressure, a small drop occurs in the value of the maximum magnitude of the peak for the leakage conditions with the semi-worn $(\approx 0.8 \mathrm{e}$ -6 ) and worn seals $(\approx 1 \mathrm{e}-6)$. This minor drop in the maximum magnitude of the peak may be due to variation in friction conditions at the piston rod seal and piston rod interface due to leakage. By using AE power spectral density feature, it is possible to identify the unworn seal condition, leakage due to semi-worn seal, and leakage due to worn seal. As it is time consuming to calculate and analyse the AE power spectral density for a large number of strokes that is typically observed in the industries, an attempt is made to further analyse using other $\mathrm{AE}$ frequency features (mean frequency, median frequency, and bandpower) that can be used for continuous monitoring of seal wear condition.

Figure 11 represents the AE frequency features calculated for each stroke for all the pressure conditions. The behaviour of $\mathrm{AE}$ mean frequency and median frequency feature is similar to that of AE time-domain features where it is possible to identify the non-leakage (unworn) and leakage conditions (semi-worn and worn). In Fig. 11b, the AE median frequency 

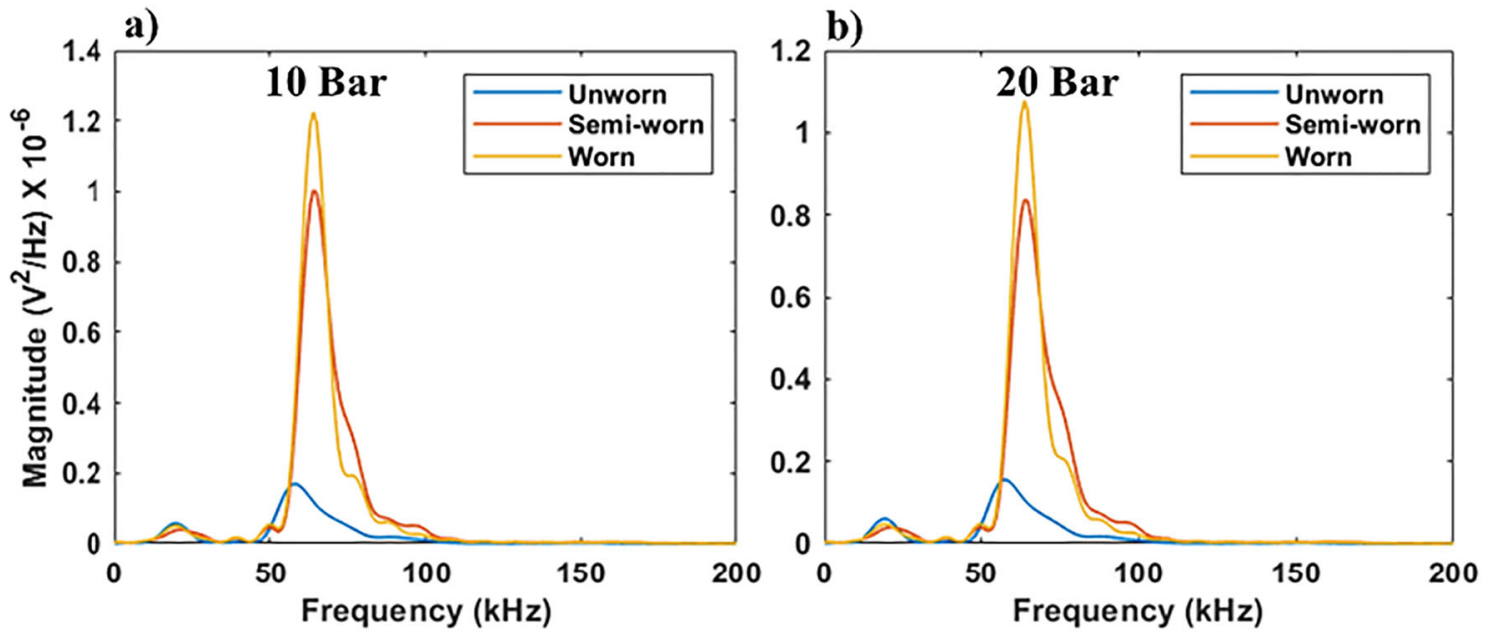

c)

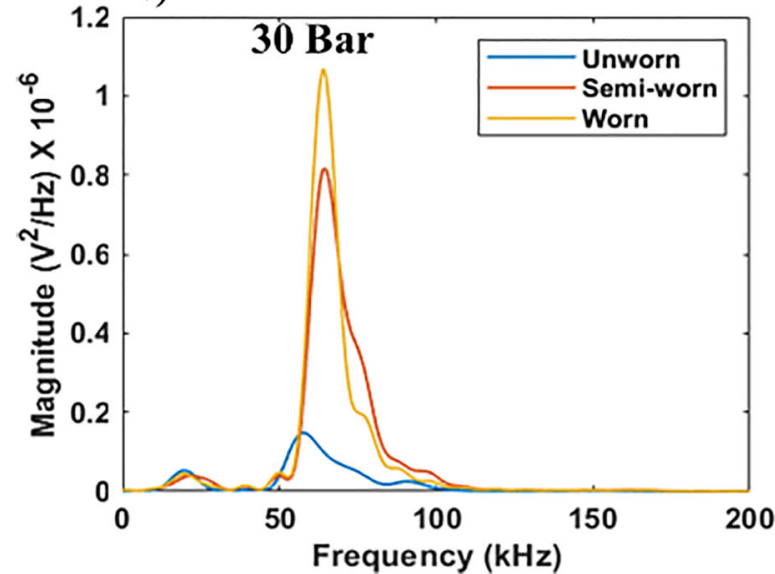

d)

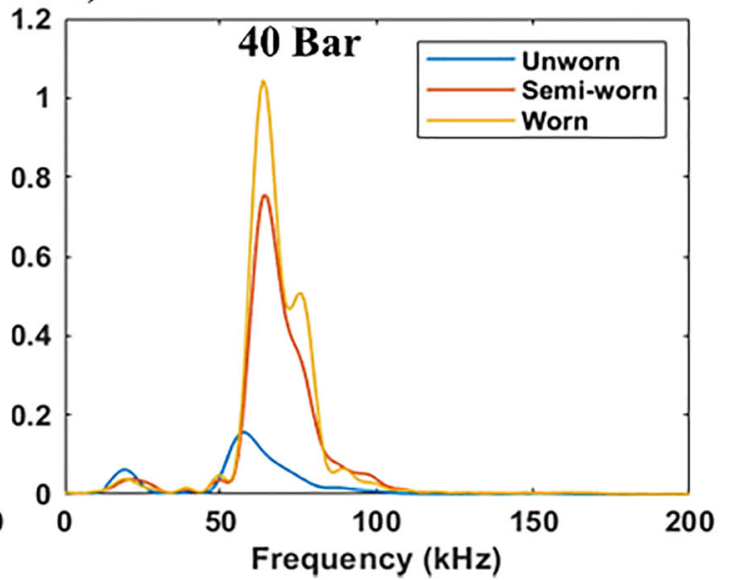

Fig. 10 Power spectral density (PSD) plot for unworn, semi-worn, and worn seal at pressure condition of a 10 bar, b 20 bar, c 30 bar, and d 40 bar. (Note: For clarity the AE frequency range has been capped to $0-200 \mathrm{kHz}$ )

feature of the semi-worn and worn seal is nearly the same. In Fig. 11c, the AE bandpower of worn seal > semi-worn seal $>$ unworn seals for all the pressure conditions. For the bandpower feature, the standard deviation is also minimal for the unworn, semi-worn, and worn seals and at each pressure conditions. Therefore, AE bandpower can be used for continuous monitoring of the piston rod seals in the hydraulic test rig.

\section{Discussion}

\subsection{AE features for continuous monitoring of seal wear}

Table 2 represents the summary of $\mathrm{AE}$ features that can be used to understand non-leakage and leakage conditions in the seal flange and leakage due to semi-worn and worn seals. From Figs. 7, 8, 9, and 11, the values of the AE features for the worn seal are lower compared with the values of the AE features of the semi-worn seal. This may be due to the severe leakage as shown in Fig. 4c. During the leakage due to semiworn seal, the fluid film between the piston rod seal and piston rod can act as a sealing element (hydrodynamic lubrication) resulting in the speed of the fluid and the piston rod of the same order of magnitude. However, in the case of heavy leakage due to worn seal, the fluid travels faster than the rod and cannot be recovered by the so-called back pressure effect. According to Tan et al. [12], the leakage acts as liquid seal and makes the stroke smoother resulting in lower signal strength. From Fig. 7a and b, the AE features mean and RMS for the worn seal are higher compared with the semiworn seal, and the AE mean and RMS rise at pressures above 30 bar. This is likely due to change in friction conditions at the piston rod seal and piston rod interface with increasing operating pressure condition. Also, the AE RMS is an energybased feature which is more suitable to interpret the change in AE signal compared with AE peak, kurtosis, and skewness 
a)

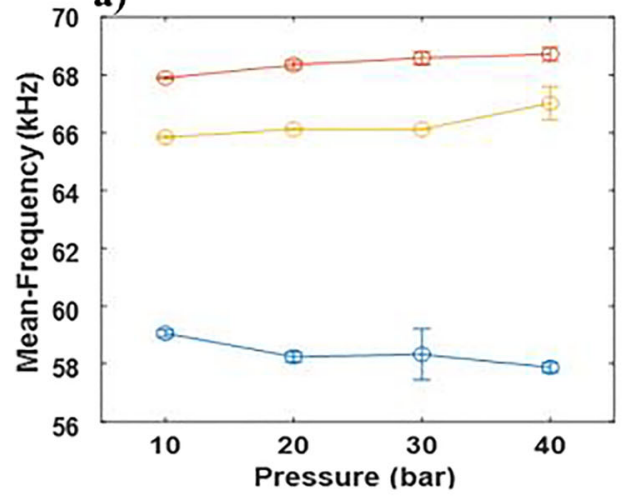

c)

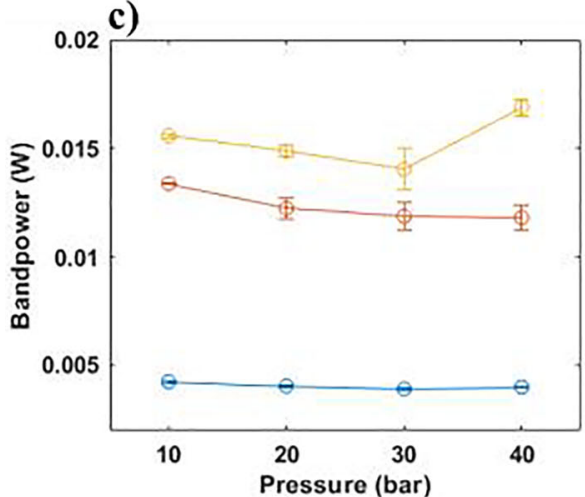

b)

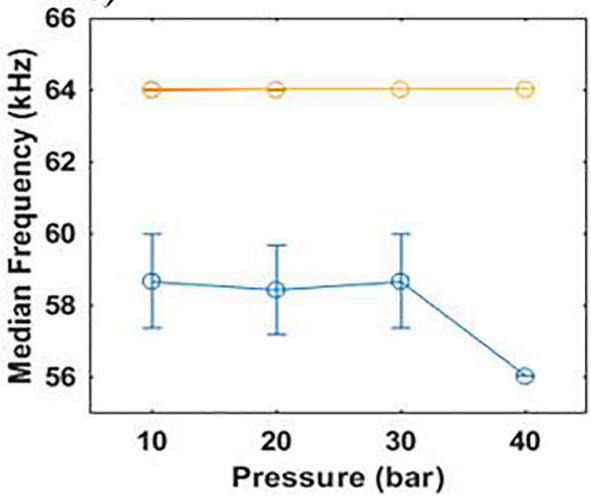

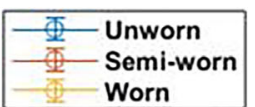

Worn

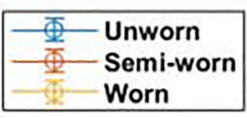

Fig. 11 Frequency domain features. a Mean frequency. b Median frequency. $\mathbf{c}$ Bandpower. (Note: Bandpower feature is calculated at frequency range of $0-200 \mathrm{kHz}$ based on AE frequency distribution observed

[8]. In the previous study of condition monitoring of water cylinders [8], the AE frequency distribution from the power spectral density due to leakage was observed in $\mathrm{AE}$ frequency range of 50-190 kHz and $190-300 \mathrm{kHz}$. The peak of frequency magnitude was observed at $120 \mathrm{kHz}$. However, in this study using AE frequency analysis (time-frequency and frequency features), it was possible to define the $\mathrm{AE}$ frequency

Table 2 Summary of AE features that can be used to understand seal degradation in test rig

\begin{tabular}{lll}
\hline Features & $\begin{array}{l}\text { Leakage vs } \\
\text { non-leakage }\end{array}$ & $\begin{array}{l}\text { Leakage due to semi-worn } \\
\text { seal and worn seal }\end{array}$ \\
\hline RMS & Yes & No \\
Peak & Yes & No \\
Kurtosis & Yes & No \\
Mean & Yes & No \\
Skewness & Yes & No \\
Median frequency & Yes & No \\
Mean frequency & Yes & No \\
Bandpower (50 to $200 \mathrm{kHz})$ & Yes & Yes \\
Power spectral density & Yes & Yes \\
\hline
\end{tabular}

range from the power spectral density feature due to the bearings $(0-30 \mathrm{kHz})$ and due to the piston rod seal $(50-100 \mathrm{kHz})$ in the cylinder head. The peak magnitude of the AE frequency was observed between 55 and $70 \mathrm{kHz}$ (Figs. 10 and 11). The peak magnitude due to non-leakage in seal flange (unworn seal) was observed in the AE frequency range of $55-60 \mathrm{kHz}$ and the peak magnitude due to the leakage in the seal flange (semi-worn and worn seal) was observed to be between 63 and $70 \mathrm{kHz}$. The difference in the $\mathrm{AE}$ frequency range due to seal wear defined in this study and the study performed by Chen et al. [8] is due to a number of factors such as test rig, fluid type in the test rig, speed and pressure adopted during the experiments, and type of $\mathrm{AE}$ data acquisition used for the study. By comparing AE frequency domain features such as mean frequency and bandpower with power spectral density plot (Figs. 10 and 11a, b), the peak magnitude of the power spectral density plot is dominant in lower frequency for the worn seal when compared with that of semi-worn seal. At pressure condition of $40 \mathrm{bar}$, in the power spectral density plot (Fig. 10d), a dominant magnitude peak can be observed at $76 \mathrm{kHz}$ for the worn seal condition. This is likely due to a change in friction condition between the piston rod seal and piston rod at 40 bar. This magnitude peak at $76 \mathrm{kHz}$ has contributed to the increase in the bandpower feature and mean 
frequency feature at 40 bars (Fig. 10a, c). Also, in the presence of wear, several resonant components are present in the frequency spectrum [17]. The presence of these resonant frequency components in between the continuous $\mathrm{AE}$ signal distribution has likely contributed to the increase in $\mathrm{AE}$ bandpower and magnitude peak in the power spectral density $[15,17,18]$. For the non-leakage condition (unworn seal), the observed magnitude peak in the power spectral density plot (Fig. 10) is due to normal friction conditions between the piston rod seal and piston rod during the piston rod movement in the test rig. For the leakage condition (semi-worn and worn seal), the magnitude peak increases with seal wear, because of the energy generated due to leakage as well as due to the friction conditions between the piston rod seal and piston rod during the piston rod movement in test rig. This increase in energy with an increase in seal wear can be also observed in the $\mathrm{AE}$ bandpower feature. Therefore, due to these reasons, the $\mathrm{AE}$ bandpower and power spectral density features show an increment in the AE feature values with the increase in seal wear condition (worn seal $>$ semi-worn seal $>$ unworn seals) when compared with the other $\mathrm{AE}$ features. Irrespective of the pressure conditions, the $\mathrm{AE}$ bandpower feature and power spectral density are able to identify the non-leakage (unworn seal) and leakage conditions (semi-worn and worn seal) in the seal flange. The AE bandpower and power spectral density feature are also able to identify and separate the AE features due to leakage from semi-worn and worn seals in the cylinder head. Therefore, AE bandpower feature and power spectral density can be used for the continuous monitoring of seal wear in the hydraulic cylinder.

\subsection{Comparison of AE features proposed in this study with the other sensor features proposed in literature}

In literature, a number of features from pressure, vibration, torque, force, and $\mathrm{AE}$ sensors have been proposed to monitor seal wear (Table 3). Among all the sensors that have been used to diagnose seal wear in hydraulic cylinders in literature, the pressure sensor is most widely used. The pressure-based features from the Hilbert Huang transform (HHT) technique have shown the capability to detect leakage as low as $0.124 \mathrm{~L} / \mathrm{min}$. The application of torque sensors to monitor seal wear in hydraulic cylinders is limited as hydraulic cylinder involves linear motion. Maximum tension force feature from force sensor has shown good sensitivity in diagnosing wear in reciprocating seals [30]. The vibration-based feature dVBrms has shown the capability to diagnose the change in loading conditions in hydraulic cylinders and can be applied to distinguish between unworn and worn seals. Chen et al. [8] proposed AE rms to diagnose leakage due to seal wear in hydraulic cylinders. It is important to note the sensor-based features proposed in literature are mainly from the experiments performed under controlled laboratory conditions. The AE features proposed in the study (AE bandpower and power spectral density) has

Table 3 Summary of sensor-based features proposed in the literature to understand seal degradation

\begin{tabular}{|c|c|c|c|c|}
\hline Sensor & Literature & Signal processing technique & Defect identified & $\begin{array}{l}\text { Sensor-based features proposed } \\
\text { in the study }\end{array}$ \\
\hline \multirow[t]{6}{*}{ Pressure } & An et al. [19] & Extended Kalman filter & Internal and external leakage & Residual pressure error \\
\hline & Goharrizi et al. $[3,20,21]$ & Wavelet transform & $\begin{array}{l}\text { Internal fluid leakage and } \\
\text { external fluid leakage }\end{array}$ & $\begin{array}{l}\text { For internal fluid leakage, RMS } \\
\quad \text { value of level two wavelet coefficient } \\
\text { For external fluid leakage, RMS } \\
\quad \text { value of level four wavelet coefficient }\end{array}$ \\
\hline & Zhao et al. [22] & & Fluid leakage levels & Wavelet packet energy variance \\
\hline & Tang et al. [4] & & Internal fluid leakage & Energy from frequency bands \\
\hline & Goharrizi et al. [23] & Hilbert Huang transform & Fluid leakage & Instantaneous magnitude of the first IMF \\
\hline & Garimella et al. [24-26] & Adaptive robust observer & Lack of supply pressure & State estimation error \\
\hline Vibration & $\begin{array}{c}\text { Tan et al. [27, 28] and } \\
\text { Yunbo et al. [29] }\end{array}$ & $\begin{array}{l}\text { Time-domain and frequency } \\
\text { domain features }\end{array}$ & Fluid leakage due to seal wear & $\mathrm{dBVrms}$ \\
\hline \multirow{2}{*}{$\begin{array}{l}\text { Acoustic } \\
\text { emission }\end{array}$} & Chen et al. [8] & & & RMS \\
\hline & Shanbhag et al. * & $\begin{array}{l}\text { Time-domain, frequency } \\
\text { domain features, and } \\
\text { STFT technique }\end{array}$ & & Bandpower and power spectral density \\
\hline Torque & Ramachandran et al. [2] & Time-domain features & & Mean, RMS, Peak, and SRA \\
\hline Force & Ramachandran et al. [30] & $\begin{array}{l}\text { Support vector machine with } \\
\text { particle swarm } \\
\text { optimisation technique }\end{array}$ & & Maximum tension force \\
\hline
\end{tabular}

${ }^{*}$ Methodology developed in this paper 
shown very good sensitivity in detecting non-leakage and leakage conditions in the seal flange, and leakage due to semi-worn and worn seals despite the noise from the linear bearings, present in the cylinder head, and also noise from the spindle, which is driving the piston rod. The AE features proposed in this study also involve low complexity in the data processing compared with techniques used for pressure and force sensing in the literature (Table 3). Therefore, this AEbased condition monitoring methodology represents a promising approach to perform further work using stud mounted AE sensors for large hydraulic cylinders [31] or by mounting $\mathrm{AE}$ sensor on the clevis part of the small hydraulic cylinders, to continuously monitor seal wear under industrial conditions and also to develop prognostics-based models to determine remaining useful life of the seal from the point where the seal starts to degrade.

\section{Conclusion}

This study investigated the wear state of hydraulic cylinder seals using $\mathrm{AE}$ on a test rig. Experiments were conducted using different wear states of the piston rod seal under different pressure conditions. A continuous AE signal was observed for each hydraulic cylinder stroke. From the AE analysis:

- Using AE time-domain features such as mean, RMS, Peak, and skewness and frequency domain features such as mean frequency and median frequency it is possible to identify and separate non-leakage and leakage conditions in the test rig.

- From the time-frequency analysis and power spectral density features, the AE frequency information of the seal wear was observed in the $\mathrm{AE}$ frequency range of $50-100$ $\mathrm{kHz}$. The peak magnitude due to non-leakage condition in seal flange was observed in the AE frequency range of 55$60 \mathrm{kHz}$ and due to leakage condition in seal flange was observed in the AE frequency range of $63-70 \mathrm{kHz}$.

- Using AE bandpower and power spectral density feature, it is possible to understand non-leakage condition in the seal flange, leakage due to semi-worn seal, and leakage due to worn seal.

The results observed from this study can be of direct interest to any industry using hydraulic cylinders to develop realtime monitoring based on $\mathrm{AE}$ to monitor seal wear and fluid spill from the hydraulic cylinders.

Funding information Open Access funding provided by NORCE Norwegian Research Centre AS. The research presented in this paper has received funding from the Norwegian Research Council, SFI Offshore Mechatronics, project number 237896.
Open Access This article is licensed under a Creative Commons Attribution 4.0 International License, which permits use, sharing, adaptation, distribution and reproduction in any medium or format, as long as you give appropriate credit to the original author(s) and the source, provide a link to the Creative Commons licence, and indicate if changes were made. The images or other third party material in this article are included in the article's Creative Commons licence, unless indicated otherwise in a credit line to the material. If material is not included in the article's Creative Commons licence and your intended use is not permitted by statutory regulation or exceeds the permitted use, you will need to obtain permission directly from the copyright holder. To view a copy of this licence, visit http://creativecommons.org/licenses/by/4.0/.

\section{References}

1. Hydraulic seals-linear (2019) Available at: https://www.tss. trelleborg.com/en/products-and-solutions/hydraulic-piston-seals. Accessed 25 Aug 2019

2. Ramachandran M, Siddique Z (2018) Statistical time domain feature based approach to assess the performance degradation of rotary seals. In ASME 2018 International Mechanical Engineering Congress and Exposition. American Society of Mechanical Engineers Digital Collection

3. Goharrizi AY, Sepehri N (2010) A wavelet-based approach for external leakage detection and isolation from internal leakage in valve-controlled hydraulic actuators. IEEE Trans Ind Electron 58(9):4374-4384

4. Tang HB, Wu YX, Ma CX (2010) Inner leakage fault diagnosis of hydraulic cylinder using wavelet energy. In Advanced Materials Research, 139, pp. 2517-2521. Trans Tech Publications

5. Ng F, Harding JA, Glass J (2017) Improving hydraulic excavator performance through in line hydraulic oil contamination monitoring. Mech Syst Signal Process 83:176-193

6. Ramachandran M, Siddique Z (2019) A data-driven, statistical feature-based, neural network method for rotary seal prognostics. J Nondestruct Eval Diagn Prognostics Eng Syst 2(2)

7. Helwig N, Pignanelli E, Schütze A (2015) Condition monitoring of a complex hydraulic system using multivariate statistics. In 2015 IEEE International Instrumentation and Measurement Technology Conference (I2MTC) Proceedings, pp. 210-215. IEEE

8. Chen P, Chua PSK, Lim GH (2007) A study of hydraulic seal integrity. Mech Syst Signal Process 21(2):1115-1126

9. Morofuji K, Tsui N, Yamada M, Maie A, Yuyama S, Li Z (2003) Quantitative study of acoustic emission due to leaks from water tanks. System 5(6):213-222

10. Ahadi M, Bakhtiar MS (2010) Leak detection in water-filled plastic pipes through the application of tuned wavelet transforms to acoustic emission signals. Appl Acoust 71(7):634-639

11. Lei Y, He Z, Zi Y, Chen X (2008) New clustering algorithm-based fault diagnosis using compensation distance evaluation technique. Mech Syst Signal Process 22(2):419-435

12. Filippov AV, Rubtsov VE, Tarasov SY (2017) Acoustic emission study of surface deterioration in tribocontacting. Appl Acoust 117: $106-112$

13. Li X (2002) A brief review: acoustic emission method for tool wear monitoring during turning. Int J Mach Tools Manuf 42(2):157-165

14. Hamdi SE, Le Duff A, Simon L, Plantier G, Sourice A, Feuilloy M (2013) Acoustic emission pattern recognition approach based on Hilbert-Huang transform for structural health monitoring in polymer-composite materials. Appl Acoust 74(5):746-757 
15. Shanbhag VV, Rolfe BF, Arunachalam N, Pereira MP (2018) Investigating galling wear behaviour in sheet metal stamping using acoustic emissions. Wear 414:31-42

16. Kehtarnavaz N (2011) Digital signal processing system design: LabVIEW-based hybrid programming. Elsevier

17. Bassiuny AM, Li X, Du R (2007) Fault diagnosis of stamping process based on empirical mode decomposition and learning vector quantization. Int J Mach Tools Manuf 47(15):2298-2306

18. Shanbhag V, Rolfe B, Pereira M (2020) Investigation of galling wear using acoustic emission frequency characteristics. Lubricants $8(3): 25$

19. An L, Sepehri N (2005) Hydraulic actuator leakage fault detection using extended Kalman filter. Int J Fluid Power 6(1):41-51

20. Goharrizi AY, Sepehri N (2009) A wavelet-based approach to internal seal damage diagnosis in hydraulic actuators. IEEE Trans Ind Electron 57(5):1755-1763

21. Goharrizi AY, Sepehri N, Wu Y (2010) A wavelet-based approach for diagnosis of internal leakage in hydraulic actuators using on-line measurements. Int J Fluid Power 11(1):61-69

22. Zhao X, Zhang S, Zhou C, Hu Z, Li R, Jiang J (2015) Experimental study of hydraulic cylinder leakage and fault feature extraction based on wavelet packet analysis. Comput Fluids 106:33-40

23. Goharrizi AY, Sepehri N (2011) Internal leakage detection in hydraulic actuators using empirical mode decomposition and Hilbert spectrum. IEEE Trans Instrum Meas 61(2):368-378

24. Garimella P and Yao B, 2002. Nonlinear adaptive robust observer for velocity estimation of hydraulic cylinders using pressure measurement only. In ASME 2002 International Mechanical Engineering Congress and Exposition (pp. 907-916). American Society of Mechanical Engineers Digital Collection
25. Garimella P, Yao B, (2005) Model based fault detection of an electro-hydraulic cylinder. In Proceedings of the 2005, American Control Conference, 2005. (pp. 484-489). IEEE

26. Garimella P, Yao B, (2003) Nonlinear adaptive robust observer design for a class of nonlinear systems. In Proceedings of the 2003 American Control Conference, 2003. (Vol. 5, pp. 43914396). IEEE

27. Tan AC, Chua PS, Lim GH (2003) Fault diagnosis of water hydraulic actuators under some simulated faults. J Mater Process Technol 138(1-3):123-130

28. Tan AC, Chua PS, Lim GH (2000) Condition monitoring of a water hydraulic cylinder by vibration analysis. J Test Eval 28(6):507-512

29. Yunbo H, Lim G, Chua P, Tan A (2001) Monitoring the condition of loaded modern water hydraulic axial piston motor and cylinder. In Proceedings of the Fifth International Conference on Fluid Power Transmission and Control (pp. 447-451)

30. Ramachandran M, Keegan J and Siddique Z, (2019). A hybrid PSO-SVM based method for degradation process prediction of reciprocating seal. In Proceedings of the Annual Conference of the PHM Society (Vol. 11, No. 1)

31. CMSS 786M SEE/AEE sensor mounting for on-line systems. http://webcon.skfcmc.com/Application\%20notes/CM3153\% 20EN\%20AE\%20Sensor\%20Mounting\%20080112.pdf. Accessed 10 June 2020

Publisher's note Springer Nature remains neutral with regard to jurisdictional claims in published maps and institutional affiliations. 